\title{
Effects of Environment on Wheat Varieties' Yellow Rust Resistance, Yield and Yield Related Traits in South-Eastern Ethiopia
}

\author{
Wubishet Alemu ${ }^{1,}$, Chemeda Fininsa ${ }^{2}$ \\ ${ }^{1}$ Oromia Agricultural Research Institute, Sinana Agricultural Research Centre, Bale-Robe, Ethiopia \\ ${ }^{2}$ Department of Plant Sciences, Haramaya University, Dire Dawa, Ethiopia \\ Email address: \\ wubtesema@gmail.com (W. Alemu),chefigu@yahoo.com (C. Fininsa) \\ ${ }^{*}$ Corresponding author
}

\section{To cite this article:}

Wubishet Alemu, Chemeda Fininsa. Effects of Environment on Wheat Varieties' Yellow Rust Resistance, Yield and Yield Related Traits in South-Eastern Ethiopia. Plant. Vol. 4, No. 3, 2016, pp. 14-22. doi: 10.11648/j.plant.20160403.11

Received: June 15, 2016; Accepted: June 27, 2016; Published: August 6, 2016

\begin{abstract}
Bread Wheat is one of Ethiopia's most important cereal crops in terms of area allocated, volume produced and the number of farmers engaged in its production. However, its production and productivity is curtailed by biotic and abiotic factors. Among biotic factors, wheat yellow rust caused by Puccinia striiformis f.sp.tritici is the most important disease. Field experiment was conducted to assess the effect of environment on wheat varieties' yellow rust resistance and yield performance at three locations, Sinana, Agarfa and Ginir in Bale in 2012 main cropping season. Six bread wheat varieties having different level of resistance to yellow rust were used in the experiment. Plots were arranged in randomized complete block design in three replication. Environment had a significant effect on epidemic development of yellow rust through its effect on growth and progress rate of the pathogen. The test locations were different in their weather variables and created significant difference $(p \leq 0.05)$ in yellow rust severity among the varieties. Due to weather variables across locations, the same variety responded differently to yellow rust severities at different locations. Environment had varying effect on yield and yield related traits. The tested bread wheat varieties had significant difference $(\mathrm{p} \leq 0.05)$ for all yield-related traits at all locations. There was inconsistent behavior of the varieties across locations for yield and yield components. Variation in the environmental factors affected wheat varieties' yellow rust resistance and yield performance. The varieties responded differently in their resistance to yellow rust and yield performance when exposed to different environments varying in minimum and maximum temperature regimes and rainfall status.
\end{abstract}

Keywords: Bread Wheat, Environment, Epidemics, Incidence, Puccinia striiformis, Severity, Triticum aestivum, Yellow Rust

\section{Introduction}

Wheat is one of Ethiopia's most important cereal crops in terms of the area allocated, volume produced and the number of farmers engaged in its production. About 4.7 million farmers produce 3.9 million tons of wheat across 1.6 million hectares of land with average productivity of 2.45 ton/ha (CSA, 2014). In 2013/14 cropping season, with a share of $15.6 \%$ and $18.1 \%$, wheat ranked third in total volume of production of grain crops and cereals respectively next to maize and tef. Ethiopia is also the most important wheat producer in sub-Saharan Africa. In the period of 2009-2011, the country ranked first both in area and production of wheat in sub-Saharan Africa with a share of $55 \%$ and $47.8 \%$, respectively (Negassa et al., 2013), showing a potential to become a regional exporter. Nationally, wheat contributes an estimated $12 \%$ to the daily per capital calorie intake, making it the third most important contributor to national calorie intake, after maize and sorghum (Guush et al., 2011).

Yellow rust is an important disease of bread wheat in the highlands of Ethiopia at altitudes ranging from 2150 to 2850 $\mathrm{m}$ above sea level. In south-eastern part of Ethiopia, yellow rust is a major threat to wheat production resulting in high 
yield and quality losses (Mulugeta, 1986; Bekele et al., 2002; Dereje, 2003). Grain yield loss of 71,28 and $12 \%$ on susceptible, moderately resistant and resistant varieties, respectively, were recorded (Dereje, 2003). Epidemics of yellow rust have become more frequent and widespread at higher elevations in south-eastern Ethiopia due to varietal susceptibility, frequent production of mega cultivars, expansion of wheat monocropping, introduction and development of new virulent races and favourable environmental factors prevailing disease development.

Yellow rust used to be limited mainly to high altitude and cooler areas but has now extended its adaptation to lower altitudes and warmer conditions. In recent years, new high temperature tolerant and aggressive strains of yellow rust have occurred in warmer areas (Hovmoller et al., 2008; Milus et al., 2009). Changes in atmospheric composition and the physical climatic factors, including temperature, rainfall pattern and intensity, and humidity with no doubt affect the economic importance, geographical distribution and management of rusts of wheat ultimately affecting wheat production. Altitude plays an important role in distribution of wheat production through its direct influence on rainfall, temperature, diseases and insects (Hailu, unpublished report). In addition to overall productivity, elevation influences plant characters such as pigmentation of glumes and awns. It has been reported that wheat grown at higher altitudes (1900-2300 m.a.s.l.) has vitreous kernels and deeper pigmentation of the spikes, while wheat grown at lower altitudes (1800-2000 m.a.s.l.) will produce yellow berry-kernel symptoms and a complete absence of pigmentation of the glumes. In Bale highlands, due to changes in environmental variables yellow rust has now widened its adaptation from higher, cooler to lower and warmer altitudes. It is now becoming a major threat in areas where it did not exist before and has caused resistance loss on wheat varieties. Therefore, this study was conducted with the objective to assess the effect of environment on wheat varieties' yellow rust resistance and yield performance.

\section{Materials and Methods}

Field experiments were conducted at three locations; at Sinana Agricultural Research Center (SARC) experimental field station and at Agarfa and Ginir farmers' field under rain fed conditions during the main cropping season in 2012 . SARC and Agarfa are located in cool, sub-humid agro climatic zone, while Ginir is in the midlands of Bale, southeastern Oromia regional state of Ethiopia. SARC and Agarfa experience a bimodal rainfall with reliable two seasons' crop growing period where wheat monocropping is predominant. The two seasons are locally named after the time of crop harvest. The main season, locally called Bona, extends from August to December and the other second season, locally called Ganna extends from March to July. Ginir experience a mono cropping season (main season) that extends from September to January. The geographical map of the experimental sites was presented here under (Figure 1).

SARC is located at $07^{\circ} 07^{\prime} \mathrm{N}$ latitude and $40^{\circ} 10^{\prime} \mathrm{E}$ longitude at $2400 \mathrm{~m}$ above sea level. The annual total rainfall ranges from 750 to $1400 \mathrm{~mm}$. The main season receives 270 to $842 \mathrm{~mm}$ rainfall, while the short season receives from 250 to $562 \mathrm{~mm}$. The mean annual minimum and maximum temperatures are 9.8 and $21^{\circ} \mathrm{C}$, respectively. The soil type is dominated by pellicvertisol which is slightly acidic. Agarfa is located around $07^{\circ} 26^{\prime} \mathrm{N}$ latitude and $39^{\circ} 87^{\prime} \mathrm{E}$ longitude at $2514 \mathrm{~m}$ above sea level. Its annual total rainfall ranges from 1000 to $1451 \mathrm{~mm}$. Mean annual minimum and maximum temperatures are 7.3 and $22.8^{\circ} \mathrm{C}$, respectively. The soil type is pellicvertisol. Ginir is located at $07^{\circ} 15^{\prime} \mathrm{N}$ latitude and $40^{\circ}$ 66' E longitude at $1972 \mathrm{~m}$ above sea level. The seasonal rainfall is $531 \mathrm{~mm}$ and its mean annual minimum and maximum temperatures are 13.4 and $25.5^{\circ} \mathrm{C}$, respectively. The soil type is vertisol.

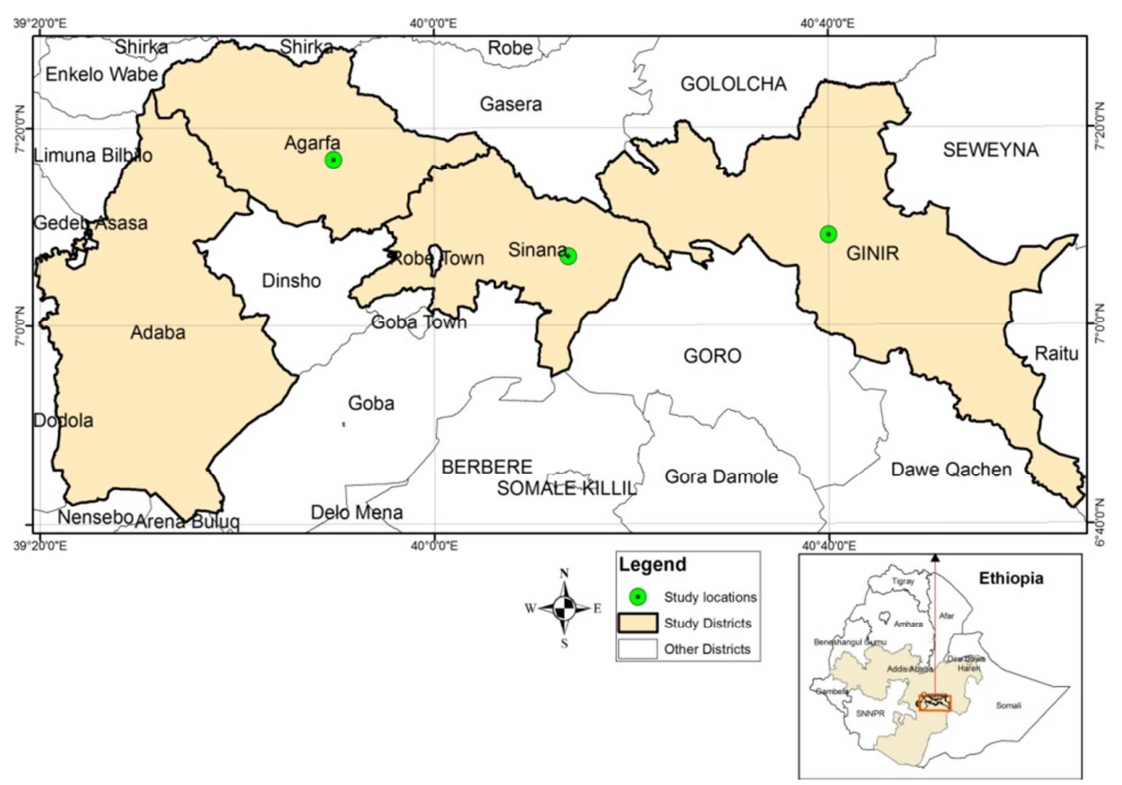

Figure 1. Geographical map showing bread wheat yellow rust experimental sites of Ginir, Sinana and Agarfa, Bale highlands. 


\subsection{Treatments, Experimental Design and Management}

Six bread wheat varieties namely, MaddaWalabu (HAR1480), Digalu (SHA 7/ KAUZ or HAR 3116), Sofumar (HAR-1889), Kubsa (HAR 1685), Millennium (ETBW4921) and Dure (HAR-1008) currently under production and having different level of resistance to yellow rust were used. Kubsa is highly susceptible to yellow rust while Dure and Millennium are susceptible and moderately susceptible, respectively. MaddaWalabu and Digalu are late maturing varieties and resistant to yellow rust while Sofumar is moderately resistant. Yellow rust was allowed to develop naturally in each variety without any artificial inoculation.

The experiment was laid out in randomized complete block design in three replications at the three locations. Eight-rowed plots of $1.6 \mathrm{~m} \times 5 \mathrm{~m}$ and $0.2 \mathrm{~m}$ spacing between rows were used. Each plot was spaced $1 \mathrm{~m}$ apart and distance between blocks was $1.5 \mathrm{~m}$. Seed rate of $150 \mathrm{~kg} \mathrm{ha}^{-1}$ was used. Plots were sown manually in rows on 8 August 2012 at Agarfa, on 29 August 2012 at Sinana and on 22 September 2012 at Ginir. At planting, recommended rates of $41 \mathrm{~kg} \mathrm{ha}^{-1}$ $\mathrm{N}$ and $46 \mathrm{~kg} \mathrm{ha}^{-1} \mathrm{P}_{2} \mathrm{O}_{5}$ were applied. Land preparation was done manually by using rake after tractor plough. Weeds were removed manually two times at the three locations. Plots were harvested on 2 January 2013 at Agarfa, on 27 January 2013 at Ginir and on 30 January 2013 at Sinana.

\subsection{Disease Assessment}

Yellow rust severity was assessed at ten days interval by estimating the approximate percentage of leaf area affected using modified Cobb scale (Peterson et al., 1948) on all tillers of 10 randomly selected plants of the central rows of each plot starting from the disease appearance. During disease assessment, the growth stage of the crop was recorded to observe onset and progress of the disease in relation to wheat phenology. Crop growth stage was assessed based on the decimalized key developed by Zadoks et al. (1974). The ten randomly selected plants were tagged with colored thread before the disease appearance. After flag leaf emergence ( 7 and 28 October 2012 at Agarfa and Sinana, respectively, and 20 November 2012 at Ginir), yellow rust severity was assessed at 10 days interval on flag (F) and penultimate (F-1) leaves of the main stems of the ten random plants in each plot. Disease severity was assessed seven times on all tillers and five times on both flag and penultimate leaves at Sinana and six times on all tillers and 5 times on both flag and penultimate leaves at Agarfa. Similarly, five times on all tillers and four times on both flag and penultimate leaves at Ginir. For all assessments, yellow rust severity was averaged for the ten plants in each plot. Yellow rust head (spike) infection was assessed on 14 December 2012 at Sinana and 1 January 2013 at Ginir on spikes of five random main stems from each plot using 0-5 scale where $0=$ no disease symptom on the spike and $5=100 \%$ of the spike infected by yellow rust. At Agarfa there was no head infection by yellow rust and hence data was not collected.
The field severity score and response for the yellow rust was converted into coefficient of infection (CI) by multiplying severity with constant value for field response as described by Yadav (1985), Stubbs et al. (1986), Roelf et al. (1992).

\subsection{Yield, Vield Components and Agronomic Data}

Plant height $(\mathrm{cm})$ : The average height of ten random plants from each plot was measured from the ground level to the top of the ear at maturity.

Kernels per spike: The average number of kernels of ten randomly selected spikes from each plot was taken at harvest.

Productive spikes per $\mathrm{m}^{2}$ : The number of productive spikes was counted from $0.5 \mathrm{~m}$ of row at the four locations within each plot at maturity and converted to per $\mathrm{m}^{2}$.

Spike length $(\mathrm{cm})$ : Spike length was measured from five randomly selected plants in each plot and averaged during analysis.

Above ground biomass (g/plot): The above ground biomass was taken from the four central rows of $4 \mathrm{~m}$ length excluding borders of $0.5 \mathrm{~m}$ length on both sides from each plot at harvest and converted in to tons per hectare $(\mathrm{t} / \mathrm{ha})$.

Grain yield (g/plot): Grain yield was adjusted to a moisture content of $12.5 \%$ and measured from the four central rows of $4 \mathrm{~m}$ length from each plot and converted in to $\mathrm{kg} / \mathrm{ha}$.

Thousand kernel weight (g): Grain yield was adjusted to a moisture content of $12.5 \%$ and the weight of 1000 -kernels sampled at random from the total grains harvested from each experimental plot was measured in (g).

Hectolitre weight $(H L W)$ : Hectolitre weight of the grain was determined in $\mathrm{kg} /$ hectolitre $(\mathrm{kg} / \mathrm{hl})$ following the AACC (1983) procedure after the moisture content was adjusted to $12.5 \%$.

\subsection{Analysis of Disease Progress}

The integral models, i.e. area under the disease progress curve (AUDPC) and growth curve functions were used. AUDPC values were calculated for each plot using the following formula (Wilcoxson et al., 1975).

$$
\text { AUDPC }=\sum_{\mathrm{i}=1}^{\mathrm{n}-1}\left[0.5\left(\mathrm{X}_{\mathrm{i}+1}+\mathrm{X}_{\mathrm{i}}\right)\right]\left[\mathrm{t}_{\mathrm{i}+1}-\mathrm{t}_{\mathrm{i}}\right]
$$

Where $x_{i}$ is the disease severity expressed in percentage at $i^{\text {th }}$ observation, $t_{i}$ is the time (days after planting) at the $i^{\text {th }}$ observation and $\mathrm{n}$ is total number of days. AUDPC was calculated separately for disease assessments made on different leaves of the plant (i.e. all leaves, flag leaves and penultimate leaves). Since AUDPC values on the different leaves and over the locations were of different epidemic duration, the values were standardized through dividing the values by the total duration $\left(t_{n}-t_{1}\right)$ of the epidemic.

\subsection{Statistical Analysis}

Data on yellow rust severity, AUDPC, yield and yield components were subjected to analysis of variance 
(ANOVA). ANOVA was done using SAS GLM Procedure (SAS version 9.00, Inst. 2002). Comparison of treatment means was made using least significant difference test (LSD).

\section{Results and Discussion}

\subsection{Disease Severity}

\subsubsection{Sinana}

Yellow rust assessments made on all leaves revealed that a maximum of 55.5, 20.8, 4.2, 1.7, 0.6 and $0.03 \%$ yellow rust severities were recorded on Kubsa, Millennium, Dure, Digalu, MaddaWalabu and Sofumar, respectively at Sinana (Figure 2). The highest disease severity was consistently observed on the susceptible variety, Kubsa. After 41 DAP, the disease increased sharply on all leaves of Kubsa, while the increment was seen after 61 DAP on Millennium and Dure. The disease severity increment was stable on the resistant varieties MaddaWalabu and Digalu and the moderately resistant variety Sofumar. Yellow rust severities recorded on the resistant and moderately resistant varieties for all assessment dates were not significantly different among each other. But there was a significant difference $(p \leq 0.05)$ in severities among susceptible, moderately resistant and resistant varieties.

Disease severities recorded on flag leaves were lower compared to the severities on all leaves for all the test varieties. The susceptible variety Kubsa had the maximum disease severity values consistently for all assessment dates. On flag leaves, a maximum of $37.1,18.3,2.6,1.3,0.5$ and $0 \%$ severities were recorded on Kubsa, Millennium, Dure, Digalu, MaddaWalabu and Sofumar, respectively, at Sinana (Figure 2). The sharp increment of the disease was observed after 61 DAP on flag leaves of Kubsa and Millennium, 71 DAP on Dure and Digalu, while a stable increment was observed on MaddaWalabu. The resistant and moderately resistant varieties were not significantly different among each other in disease severity recorded on all assessment dates. There was significant difference $(p \leq 0.05)$ in yellow rust severities on flag leaves among susceptible, moderately resistant and resistant varieties.

Yellow rust severity on F-1 leaves revealed that the highest severity was recorded on the susceptible variety Kubsa at Sinana. On 91 DAP the highest (55.3\%) disease severity was recorded on F-1 leaves of Kubsa whereas variety Millennium, Dure, Digalu, MaddaWalabu and Sofumar had $12.03,2.4,0.43,0.05$ and $0.03 \%$, respectively, at Sinana (Figure 2).

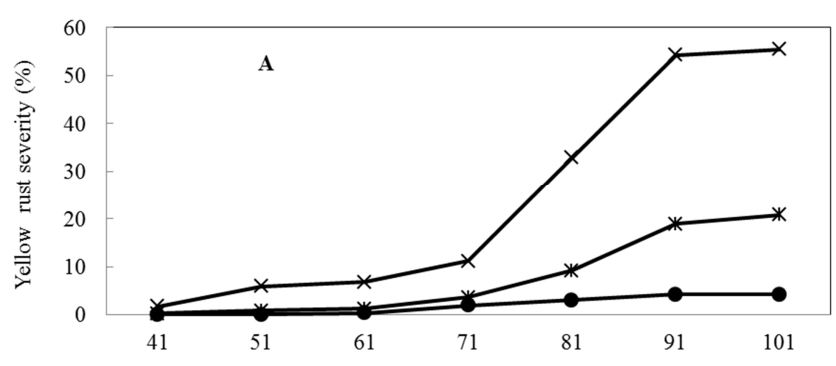

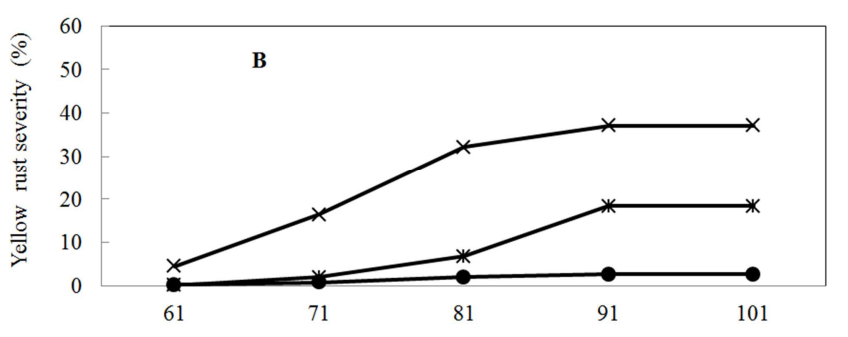

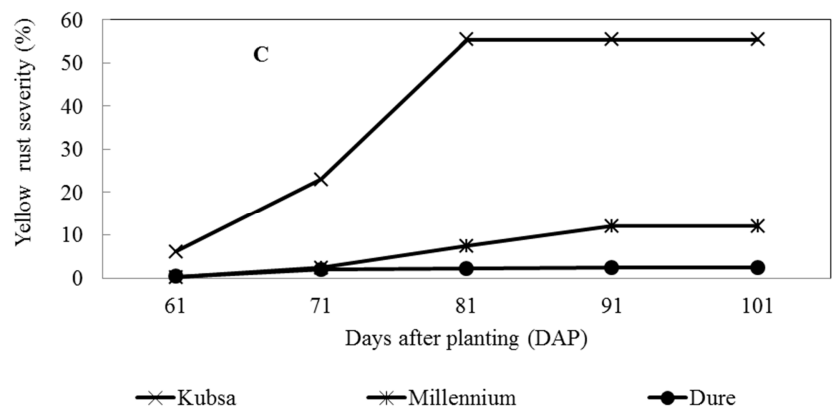

Figure 2. Yellow rust severity progress curves on bread wheat varieties at Sinana in 2012. Disease assessment was made on all leaves (A) and flag leaves (B) and penultimate leaves $(C)$ of each variety at 10-days interval.

\subsubsection{Agarfa}

Generally disease severity at Agarfa was lower compared to Sinana for all the varieties on all assessment dates. Out of the six test varieties, yellow rust epidemic developed only on the susceptible and moderately susceptible varieties, Kubsa and Millennium, respectively. The maximum mean disease severity on all leaves was $16.7 \%$ on the susceptible variety Kubsa and $9.6 \%$ on Millennium (Figure 3). The disease increased sharply after 70 and 60 DAP on all leaves of Millennium and Kubsa, respectively. There was significant difference $(p \leq 0.05)$ in yellow rust severity between the susceptible variety Kubsa and resistant varieties (MaddaWalabu and Digalu). But there was no significant difference among the resistant and moderately resistant varieties. A significant difference severity level on all leaves was also observed between Kubsa and Millennium on the final date of disease assessment.

On flag leaves disease severity increased after 70 and 60 DAP on Millennium and Kubsa, respectively (Figure 3). The mean disease severity on flag leaves of Kubsa was lower than that of all leaves, while the severity on flag leaves of Millennium was higher than that of all leaves. Maximum of 15 and $10.8 \%$ disease severities were recorded on flag leaves of Kubsa and Millennium, respectively, at Agarfa. After 80 DAP a significant difference in yellow rust severity was observed between Kubsa and Millennium.

Yellow rust severity assessed on F-1 leaves of Kubsa and Millennium was lower than the severity assessed on all and flag leaves. Disease severity on F-1 leaves increased sharply after 60 and 70 DAP on Kubsa and Millennium, respectively. Maximum mean disease severities of 13.5 and $7.6 \%$ were recorded on Kubsa and Millennium, respectively (Figure 3). Kubsa and Millennium showed significant difference in yellow rust severity during all the assessment dates except on 80 DAP. There was significant difference in yellow rust 
severities on F-1 leaves between the susceptible variety Kubsa and the resistant varieties at Agarfa during all the assessment dates.
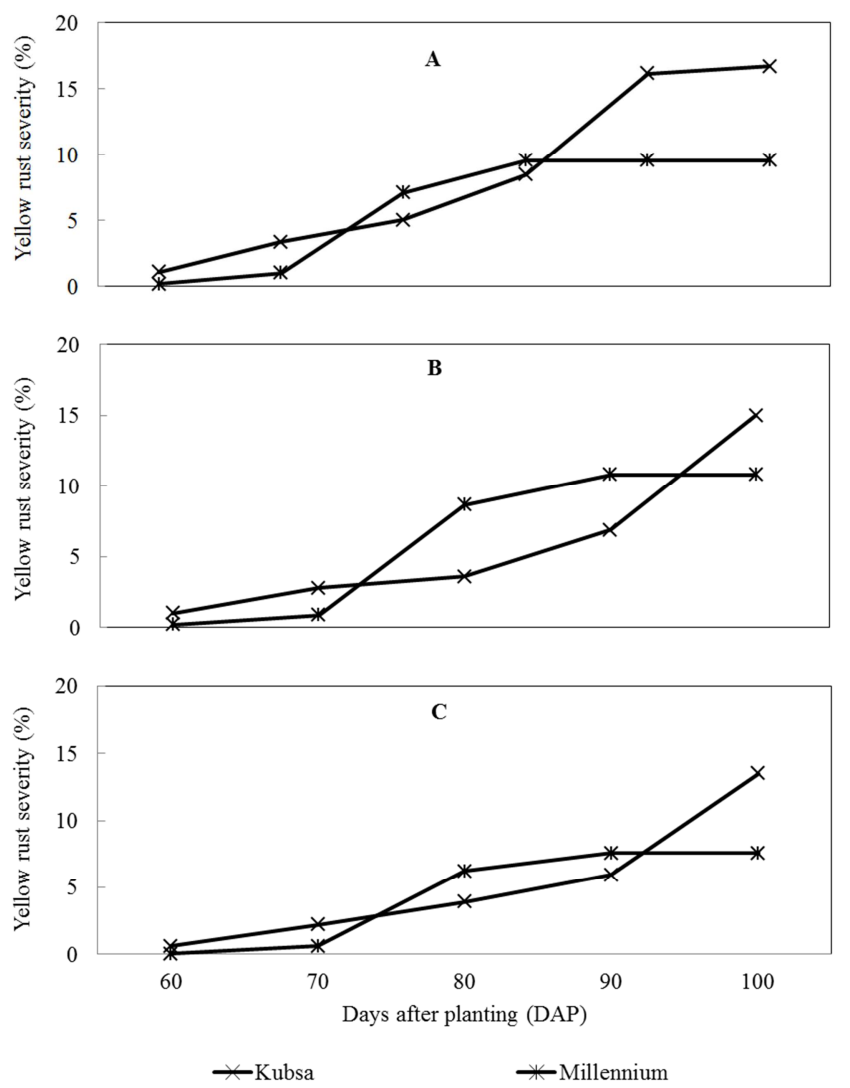

Figure 3. Yellow rust severity progress curves on bread wheat varieties at Agarfa in 2012. Disease assessment was made on all leaves (A), flag leaves (B) and penultimate leaves (C) of each variety at 10-days interval.

\subsubsection{Ginir}

Based on the assessments made on all leaves, disease severity was lower on the susceptible variety Kubsa at Ginir than at Sinana, while the severity was higher than at Agarfa. A maximum of $41.9,14.9$ and $21.5 \%$ yellow rust severities were recorded on Kubsa, Millennium and Dure, respectively, at Ginir (Figure 4). A sharp increment of the disease was observed after 49 DAP on all leaves of the three test varieties. At the time of disease onset (49 and 59 DAP), yellow rust severity on all leaves was not significantly different among Kubsa, Millennium and Dure. But the severities were significantly different among MaddaWalabu, Digalu and Sofumar. The varieties showed significant difference in yellow rust severity at 69 DAP. The final date of disease severity (89 DAP) on the highly susceptible variety Kubsa was significantly different from the rest of the test varieties.

Yellow rust severities recorded on flag leaves of Kubsa, Millennium and Dure were lower than the severities recorded on all leaves. On flag leaves, maximum of 40.6, 9.1 and $21.3 \%$ yellow rust severities were recorded on Kubsa, Millennium and Dure, respectively (Figure 4). The disease increased sharply after 59 DAP on flag leaves of Kubsa and Dure, while the increment was pronounced after 69 DAP on
Millennium. A significant difference in yellow rust severities on flag leaves was observed between the highly susceptible variety Kubsa and Millennium and Dure at 59 and 89 DAP.

Disease severities assessed on F-1 leaves of Kubsa and Dure were lower than the severities recorded on all and flag leaves on the same varieties, whereas yellow rust severity recorded on F-1 leaves of Millennium was higher than that of the flag leaf. The disease severity increment on F-1 leaves was observed after 59 DAP on Kubsa, Millennium and Dure. Maximum mean disease severities of 19.2, 12 and 9.9\% were recorded on Kubsa, Millennium and Dure, respectively, at Ginir (Figure 4). The highly susceptible variety Kubsa showed significant difference in yellow rust severity as compared to the other varieties during all the assessment dates.
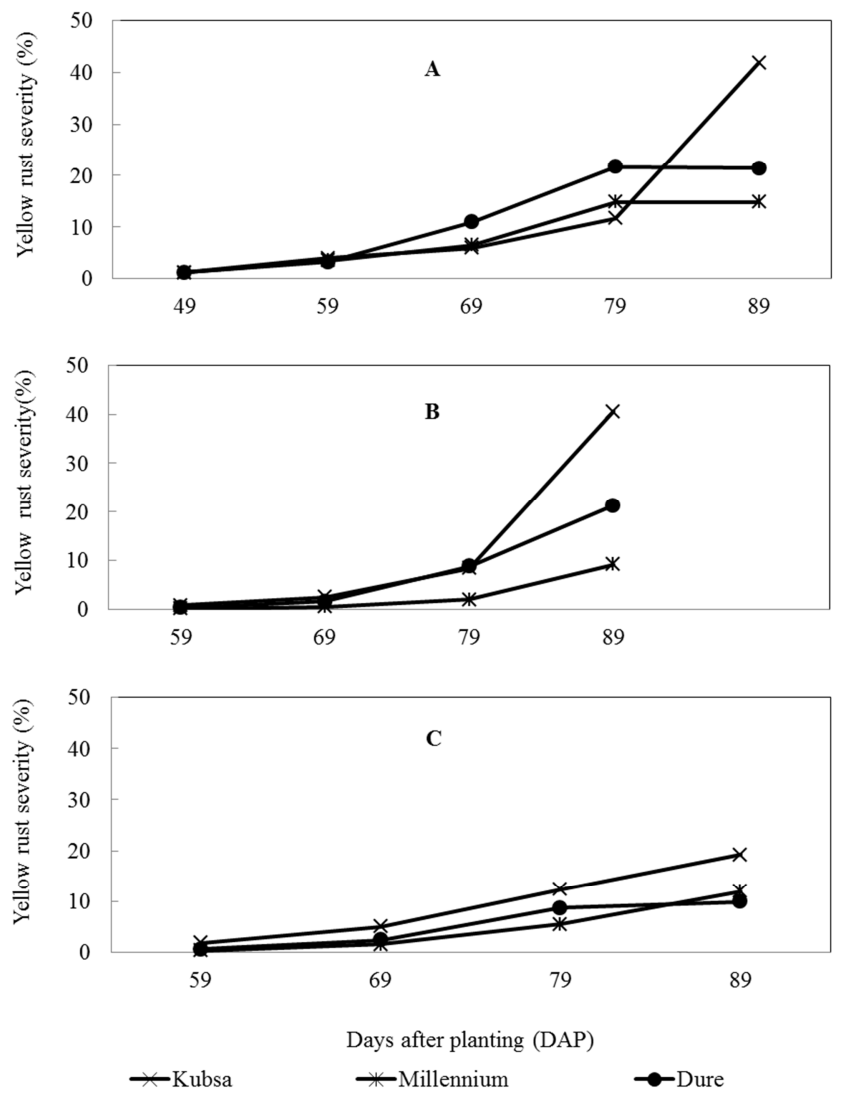

Figure 4. Yellow rust severity progress curves on bread wheat varieties at Ginir in 2012. Disease assessment was made on all leaves (A) and flag leaves (B) and penultimate leaves $(C)$ of each variety at 10-days interval.

The present study indicated that yellow rust epidemic development on all leaves, flag leaves and F-1 leaves was different for diverse varieties at all environments. This is explained by changes in environmental variables and aggressiveness of the pathogen over locations. Andrivon (1993) stated that aggressiveness of an isolate is influenced by both host plant response and environment. Changes in environmental factors also modify host morphology, physiology and resistance. This is in agreement with YañezLópez et al. (2012) who reported that climate change modifies host physiology and resistance, and alter the stages 
and rates of the development of pathogens. The result of the current study also showed that rate of yellow rust development was different for the test varieties at different locations.

Yellow rust progress curves on different leaf positions for the three locations generally attained typical sigmoid shape for Kubsa, Millennium and Dure. Such disease progress curves are characteristic of polycyclic diseases (Van der Plank, 1963). The yellow rust epidemic development showed that disease progress curves vary depending on the resistance level of the variety and the prevailing environmental factors. The difference in magnitude and shape of yellow rust progress curves at Sinana, Agarfa and Ginir shows the effects of environmental factors on disease progress and final disease development as stated by Campbell and Madden (1989).

Yellow rust epidemics lasted to the end of crop maturity and resulted in head infection on Kubsa, Millennium, Dure, MaddaWalabu and Sofumar at Sinana and on Kubsa and Millennium at Ginir. The maximum head infection was observed on the susceptible variety Kubsa at both Sinana and Ginir locations. There was significant difference between the susceptible and moderately resistant and resistant varieties in head infection at both locations. However, there was no significant difference among the moderately resistant and resistant varieties in terms of head infection at these locations (Sinana and Ginir). On the highly infected variety Kubsa, the grains were shrivelled and resulted in losses in yield, yield components and hectolitre weight at Sinana. This current result is consistent with the findings of Purdy and Allan (1965) who indicated that head infection by yellow rust, which influences yield is an important factor.

Little infection on the moderately resistant and resistant varieties did not result in shrivelling of kernels and corresponding losses in yield and yield components at Sinana. Moderately resistant and resistant varieties were free of yellow rust head infection at all locations except that at Sinana insignificant little infection was observed on these varieties. Higher head infection was recorded at Sinana than that of Ginir, whereas at Agarfa there was no head infection at all even on the highly susceptible variety.

The current study clearly showed that environmental variability had a significant effect on epidemic development of yellow rust through its effect on growth and progress rate of the pathogen. The test locations were different in their weather variables and created significant difference in yellow rust severity among the varieties. Due to these weather variables across locations, the same variety responded differently to yellow rust severities at different locations.

\subsection{Effect of Environment on Wheat Yield and Yield Components}

Statistical analysis of the data revealed that environment had varying effect on yield and yield components. Similarly, the tested bread wheat varieties had significant difference ( $p \leq$ 0.05 ) for all yield-related traits. This revealed inconsistent behavior of the varieties across locations for their yield and yield components. At Sinana, comparison of mean values revealed that there was significant difference among yields of wheat varieties. The susceptible variety Kubsa responded the lowest yield $\left(1739.20 \mathrm{~kg} \mathrm{ha}^{-1}\right)$, while the resistant variety Digalu gave the highest yield $\left(3866.60 \mathrm{~kg} \mathrm{ha}^{-1}\right)$. The other varieties vis-à-vis MaddaWalabu, Sofumar, Dure and Millennium gave 3212.30, 2781.50, 2756.20 and $2440.0 \mathrm{~kg}$ $\mathrm{ha}^{-1}$, respectively, at Sinana (Table 1). Significant differences in thousand-kernel weight and hectolitre weight were observed between the highly susceptible variety, Kubsa, and the rest of the varieties. However, there was no significant difference among all the varieties in their productive spikes $\mathrm{m}^{-2}$. The mean values of plant height, kernels spike ${ }^{-1}$, spike length and aboveground biomass significantly varied among the test varieties.

At Agarfa, the analysis of variance showed that variation among the varieties in agronomic parameters was not that much significant as compared to that of Sinana. Based on the analysis, the highest $\left(3097.10 \mathrm{~kg} \mathrm{ha}^{-1}\right)$ grain yield was obtained from MaddaWalabu, while the lowest $(1664.80 \mathrm{~kg}$ $\mathrm{ha}^{-1}$ ) from Dure. The other commercial varieties Kubsa, Digalu, Sofumar and Millennium gave grain yield of 2487.90, 2221.60, 2080.70 and $2046.90 \mathrm{~kg} \mathrm{ha}^{-1}$, respectively (Table 2). This result showed that the highly susceptible variety Kubsa gave higher yield than even that of the resistant varieties. This is because the yellow rust pressure was typically very low to differentiate the varieties in their resistance levels. Therefore, from this result it is possible to conclude that the susceptible variety Kubsa is high yielder in areas where yellow rust severity is very low.

Based on the statistical analysis, maximum grain yield was obtained from the moderately susceptible variety, Millennium, while the minimum from the highly susceptible variety, Kubsa, at Ginir. Grain yields of 3106.10, 2917.50, $2800.70,2730.0,2613.10$ and $2317.10 \mathrm{~kg} \mathrm{ha}^{-1}$ were obtained from Millennium, MaddaWalabu, Digalu, Dure, Sofumar and Kubsa, respectively (Table 3). However, significant difference in grain yield was observed between Kubsa and Millennium and MaddaWalabu. Similarly, there was a significant difference in thousand-kernel weight between the highly susceptible variety and the rest of the varieties. Variation in plant height, kernels spike $^{-1}$, spike length, productive spikes $\mathrm{m}^{-2}$, aboveground biomass and hectolitre weight was also observed among the varieties.

The results of this study demonstrated that variation in the environmental factors affected wheat varieties' yellow rust resistance and yield performance. In the present study, the six varieties responded differently in their resistance to yellow rust and yield performance when exposed to different environments varying in minimum and maximum temperature regimes and rainfall status. This might be due to changes in physiology of both the host plant and the pathogen as a result of changes in the environmental variables. Under current climate, crop loss from diseases in a changed climate will be determined by a large number of interacting factors that directly and indirectly influence plant diseases (Chacraborty et al., 2000). Among direct effects, 
altered physiology and morphology of the host under elevated $\mathrm{CO}_{2}$ would change the interception of light and precipitation, and modify canopy structure and microclimate to influence disease epidemiology. Earlier works also suggested that wheat plant continues robust growth for a longer time at optimum temperature i.e., $25^{\circ} \mathrm{C}$, which enhances grain filling period and resultantly express maximum yield. The growth continues at lower temperatures $\left(3-4^{\circ} \mathrm{C}\right)$ or at higher temperatures $\left(30-32^{\circ} \mathrm{C}\right)$ but lower temperatures retards the growth while higher temperatures accelerate maturity (Khan, 2003). Increases in temperature can modify host physiology and resistance. A rise in temperature above $20^{\circ} \mathrm{C}$ can inactivate temperature-sensitive resistance to stem rust in oat cultivars with pg3 and pg4 genes (Martens et al., 1967). In contrast, lignifications of cell walls increased in forage species at higher temperature (Wilson et al., 1991) to enhance resistance to fungal pathogens (Strange, 1993). Similarly, other works also dictates that changes in precipitation have more pronounced effects on the development of many plant diseases, particularly those caused by fungal pathogens. In the present study, the yellow rust severity assessed on the test cultivars was almost comparable at the highland and mid-land agroecological zones. This demonstrates that the pathogen is extending its adaptation from the high, cool areas to the warmer areas in Bale.

Environment may affect the availability, growth stage, succulence and genetic susceptibility to diseases of plants (Agrios, 2005). Therefore, crop production is extremely susceptible to climate change. The effect of climate change is highly variable and dependent on the region. Climate change affects temperature, precipitation, $\mathrm{CO}_{2}$ levels and frequency of extreme weather events. These will have a significant effect on agricultural production and the temporal and spatial distribution of pests and diseases (Nicholls, 1997; Peng et al., 2004; Rosenzweig and Tubiello, 2007; Ghini et al., 2008). In this study the same scenario was observed. Daily maximum and minimum temperature and total rainfall were different at the test locations. Variability in these environmental factors significantly affected the yield performance of the varieties across locations where by creating significant difference among varieties in their resistance and susceptibility to yellow rust infection.

Table 1. Yield and yield components of six bread wheat varieties at Sinana, 2012 main cropping season.

\begin{tabular}{llllllllll}
\hline Variety & PH $(\mathbf{c m})$ & $\mathbf{K} / \mathbf{s p}$ & $\mathbf{S P} / \mathbf{m}^{2}$ & $\mathbf{S L}(\mathbf{c m})$ & $\mathbf{B M}(\mathbf{t} / \mathbf{h a})$ & $\mathbf{G Y}(\mathbf{k g} / \mathbf{h a})$ & TKW $(\mathbf{g})$ & HLW \\
\hline Kubsa & 79.67 & 43.10 & 333.00 & 7.73 & 6.77 & 1739.20 & 24.59 & 72.00 \\
Millennium & 75.87 & 52.4 & 304.67 & 6.93 & 6.56 & 2440.00 & 32.36 & 80.93 \\
Dure & 89.27 & 40.77 & 313.67 & 7.53 & 8.33 & 2756.20 & 39.06 & 82.27 \\
Maddawalabu & 88.57 & 44.77 & 339.67 & 10.40 & 9.38 & 3212.30 & 42.13 & 79.80 \\
Sofumar & 91.37 & 46.63 & 361.00 & 8.57 & 8.33 & 2781.50 & 37.36 & 81.47 \\
Digalu & 108.9 & 54.97 & 367.00 & 7.39 & 12.50 & 3866.60 & 35.13 & 82.40 \\
Mean & 88.94 & 47.11 & 336.50 & 8.09 & 8.65 & 2799.29 & 35.10 & 79.81 \\
CV (\%) & 1.99 & 3.65 & 11.75 & 4.39 & 10.64 & 8.85 & 3.96 & 1.22 \\
SE & 1.77 & 1.72 & 39.53 & 0.36 & 0.92 & 247.60 & 1.39 & 0.97 \\
LSD (0.05) & 3.22 & 3.13 & NS & 0.65 & 1.67 & 450.51 & 2.53 & 1.77 \\
\hline
\end{tabular}

$\mathrm{PH}=$ plant height, $\mathrm{K} / \mathrm{ps}=$ number of kernels per spike, $\mathrm{SP} / \mathrm{m}^{2}=$ number of productive spikes $\mathrm{m}^{2}, \mathrm{SL}=$ spike length, $\mathrm{BM}=$ above ground biomass, $\mathrm{GY}=$ grain yield, TKW $=1000$-kernel weight, $\mathrm{HLW}=$ hectolitre weight

${ }^{1}$ standard error of means

$\mathrm{NS}=$ Non significant difference

Table 2. Yield and yield components of six bread wheat varieties at Agarfa, 2012 main cropping season.

\begin{tabular}{|c|c|c|c|c|c|c|c|c|}
\hline Variety & PH (cm) & $\mathrm{K} / \mathrm{sp}$ & $\mathrm{SP} / \mathrm{m}^{2}$ & $\mathrm{SL}(\mathrm{cm})$ & BM (t/ha) & GY (kg/ha) & TKW (g) & HLW \\
\hline Kubsa & 84.93 & 39.33 & 430.33 & 7.20 & 7.29 & 2487.90 & 33.80 & 81.07 \\
\hline Millennium & 77.33 & 40.23 & 490.00 & 7.44 & 7.81 & 2046.90 & 31.79 & 84.40 \\
\hline Maddawalabu & 87.80 & 42.50 & 379.00 & 8.84 & 10.31 & 3097.10 & 44.28 & 80.40 \\
\hline Sofumar & 97.27 & 37.00 & 512.33 & 7.42 & 7.29 & 2080.70 & 39.37 & 84.13 \\
\hline Digalu & 93.53 & 46.63 & 458.33 & 5.60 & 7.27 & 2221.60 & 37.79 & 84.00 \\
\hline Mean & 89.28 & 39.68 & 453.06 & 7.11 & 7.65 & 2266.50 & 37.94 & 82.96 \\
\hline CV $(\%)$ & 4.51 & 10.49 & 13.09 & 7.30 & 10.81 & 13.26 & 5.98 & 1.20 \\
\hline $\mathrm{SE}^{1}$ & 4.03 & 4.17 & 59.30 & 0.52 & 0.83 & 300.50 & 2.27 & 0.99 \\
\hline $\operatorname{LSD}(0.05)$ & 7.32 & 7.58 & 107.86 & 0.94 & 1.51 & 546.77 & 4.13 & 1.82 \\
\hline
\end{tabular}

$\mathrm{PH}=$ plant height, $\mathrm{K} / \mathrm{ps}=$ number of kernels per spike, $\mathrm{SP} / \mathrm{m}^{2}=$ number of productive spikes $\mathrm{m}^{2}, \mathrm{SL}=$ spike length, $\mathrm{BM}=$ above ground biomass, $\mathrm{GY}=$ grain yield, TKW $=1000$-kernel weight, HLW $=$ hectolitre weight

${ }^{1}$ standard error of means 
Table 3. Yield and yield components of six bread wheat varieties at Ginir, 2012 main cropping season.

\begin{tabular}{|c|c|c|c|c|c|c|c|c|}
\hline Variety & PH (cm) & $\mathrm{K} / \mathbf{s p}$ & $\mathrm{SP} / \mathrm{m}^{2}$ & SL (cm) & BM (t/ha) & GY (kg/ha) & TKW (g) & HLW \\
\hline Kubsa & 78.60 & 48.80 & 388.33 & 8.69 & 6.25 & 2317.10 & 27.81 & 77.47 \\
\hline Millennium & 79.50 & 52.63 & 385.33 & 8.76 & 7.81 & 3106.10 & 32.17 & 80.53 \\
\hline Dure & 90.40 & 46.53 & 492.00 & 8.36 & 6.15 & 2730.00 & 36.51 & 82.00 \\
\hline Maddawalabu & 86.47 & 47.40 & 431.67 & 10.17 & 7.81 & 2917.50 & 36.04 & 76.93 \\
\hline Sofumar & 87.33 & 44.13 & 497.00 & 8.63 & 6.77 & 2613.10 & 33.62 & 80.53 \\
\hline Digalu & 93.03 & 58.20 & 319.33 & 7.38 & 8.33 & 2800.70 & 36.16 & 82.40 \\
\hline CV (\%) & 2.43 & 6.25 & 17.13 & 4.89 & 14.53 & 9.78 & 6.65 & 2.14 \\
\hline $\mathrm{SE}^{1}$ & 2.09 & 3.10 & 71.80 & 0.42 & 1.04 & 268.70 & 2.24 & 1.71 \\
\hline $\operatorname{LSD}(0.05)$ & 3.80 & 5.65 & 130.53 & 0.77 & 1.89 & 488.88 & 4.08 & 3.12 \\
\hline
\end{tabular}

$\mathrm{PH}=$ plant height, $\mathrm{K} / \mathrm{ps}=$ number of kernels per spike, $\mathrm{SP} / \mathrm{m}^{2}=$ number of productive spikes $\mathrm{m}^{2}, \mathrm{SL}=$ spike length, $\mathrm{BM}=$ above ground biomass, $\mathrm{GY}=$ grain yield, TKW $=1000$-kernel weight, HLW= hectolitre weight

${ }^{1}$ standard error of means

\section{Conclusions}

Environmental variability has significant effect on epidemic development of yellow rust through its effect on growth and progress rate of the pathogen. Differences in weather variables across locations created significant difference in yellow rust severity among the varieties. The same variety responded differently to yellow rust severities at different locations due to weather variables. Yellow rust severity assessed on the test cultivars was almost comparable at the highland and mid-land agro-ecological zones. This demonstrates that the pathogen is extending its adaptation from the high, cool areas to the warmer areas in Bale. Variation in environmental factors affected wheat varieties' yellow rust resistance and yield performance. Variability in environmental factors significantly affected the yield performance of the varieties across locations where by creating significant difference among varieties in their resistance and susceptibility to yellow rust infection.

\section{References}

[1] AACC (American Association of Cereal Chemists).1983. Applied methods. American Association of Cereal Chemists. St. Paul, Minnesota, USA.

[2] Agrios G N. 2005. Plant pathology. $5^{\text {th }}$ Ed. Elsevier, USA. 922 pp.

[3] Andrivon D. 1993. Nomenclature for pathogenicity and virulence: The need for precision. Phytopathology, 83: 889890.

[4] Bekele H, Shambel K. and Dereje H. 2002. Seasonal variations in the occurrence of wheat stripe rust in Bale highlands. Pest Management Journal of Ethiopia, 6: 65-72.

[5] Campbell CC and Madden LV 1989. Introduction to plant disease epidemiology. Raleigh, North Carolina, Wooster Ohio. $507 \mathrm{p}$.

[6] Chakraborty S, Tiedemann AV and Teng PS. 2000. Climate change: potential impact on plant diseases. Keynote review. Environmental Pollution, 108: 317-326.
[7] CSA (Central Statistical Authority). 2014. Agricultural survey sample. Report on area and production of crops (private peasant holding, meher season). Statistical Bulletin No 33 . Addis Ababa, Ethiopia.

[8] Dereje H. 2003. Effects of yellow rust (Puccinia striiformis) on yield, yield components and quality of improved bread wheat (Triticum aestivum L.) varieties (Published M.Sc. Thesis). Alemaya University, Haramaya, Ethiopia.

[9] Ghini R, Hamada E and Bettiol W. 2008. Climate change and plant disease. Science and Agriculture (Piracicaba, Braz.), 65: 98-107.

[10] Guush B, Zelekawork P, Kibrom T and Seneshaw T. 2011. Food grain consumption and calorie intake patterns in Ethiopia. ESSP II Working Paper No. 23.

[11] Hovmoller MS, Yahyaoui AH, Miles EA and Justesen AF. 2008. Rapid global spread of two aggressive strains of a wheat rust fungus. Molecular Ecology, 17: 3818-3826.

[12] Khan MA. 2003. Wheat crop management for yield maximization. Wheat Research Institute, Faisalabad. 17 p.

[13] Martens JW, McKenzie RIH and Green GJ. 1967. Thermal stability of stem rust resistance in oat seedlings. Canadian Journal of Botany, 45: 451-58.

[14] Milus EA, Kristensen K and Hovmoller M. 2009. Evidence of increased aggressiveness in a recent wide spread strain of Puccinia striiformis f.sp. tritici causing stripe rust of wheat. Phytopathology, 99: 89-94.

[15] Mulugeta N. 1986. Estimates of phenotypic diversity and breeding potential of Ethiopian wheat. Hereditas, 104: 41-48.

[16] Negassa A, Shiferaw B, Jawoo K, Sonder K, Smale M, Braun HJ, Gbegbelegbe S, ZheGuo, Hodson D, Wood S, Payne T. and Abeyo B. 2013. The potential for wheat production in Africa: Analysis of biophysical suitability and economic profitability. Centro International de Mejoramiento de Maíz y Trigo (CIMMYT), México.

[17] Nicholls N. 1997. Increased Australian wheat yields due to recent climate trends. Nature, 387: 484-485.

[18] Peng SB, Huang JL, Sheehy JE, Laza RC, Visperas RM, Zhong XH, Centeno GS, Khush GS and Cassman KG. 2004. Rice Yields Decline with Higher Night Temperature from Global Warming. Proc. Natl. Acad. Sci. 101: 9971-9975. 
[19] Peterson RF, Campbell AB and Hannah AE. 1948. A diagrammatic scale for estimating rust intensity of leaves and stem of cereals. Canadian J. Res. Sect. C. 26: 496-500.

[20] Purdy LH and Allan RE. 1965. Stripe rust head infection in five Pacific Northwest wheats. Plant Disease Reporter, 49: $335-338$.

[21] Roelfs AP, Singh RP and Saari EE. 1992. Rust diseases of wheat: concepts and methods of disease management. Centro International de Mejoramiento de Maíz y Trigo (CIMMYT), México. 81p.

[22] Rosenzweig C and Tubiello FN. 2007. Adaptation and mitigation strategies in agriculture: an analysis of potential synergies. Mitig. Adapt. Strat. Global Change, 12: 855-873.

[23] Strange RN. 1993. Plant Disease Control: Towards Environmentally Acceptable Methods. London: Chapman \& Hall.

[24] Stubbs RW, Prescott JM, Saari EE and Dubin HJ. 1986. Cereal disease methodology manual. Centro International de Mejoramiento de Maíz y Trigo (CIMMYT), México.
[25] Van der Plank JW. 1963. Plant diseases: epidemics and control. Academic Press, New York. 349p.

[26] Wilcoxson RD, Skovmand B and Atif AH. 1975. Evaluation of wheat cultivars ability to retard development of stem rust. Annals of Applied Biology, 80: 275-2181.

[27] Wilson JR, Deinum B and Engels FM. 1991. Temperature effects on anatomy and digestibility of leaf and stem of tropical and temperate forage species. Netherland Journal of Agriculture Science, 39: 31-48.

[28] Yadav B. 1985. Evaluation of spring wheat lines for slow leaf rusting. Annual Biology, India, 1: 165-170.

[29] Yáñez-López R, Torres-Pacheco I, Guevara-González RG, Hernández-Zul MI, Quijano-Carranza JA and Rico-García E. 2012. The effect of climate change on plant diseases. African Journal of Biotechnology, 11 (10): 2417-2428.

[30] Zadoks JC, Chang TT and Kanzak CF. 1974. A decimal code for the growth stage of cereals. Weed Research, 14: 415-421. 